\title{
Beta Globulin
}

National Cancer Institute

\section{Source}

National Cancer Institute. Beta Globulin. NCI Thesaurus. Code C16335.

A type of globulin in plasma that in electrically charged solutions exhibits colloidal mobility between that of the alpha and gamma globulins. 